Przegląd Prawa Konstytucyjnego

----ISSN 2082-1212-----

DOI 10.15804/ppk.2020.06.55

-----No. $6(58) / 2020-----$

Jacek Zaleśny ${ }^{1}$

\title{
Review. Anahit Manasyan, Constitutional Stability as an Important Prerequisite for Stable Democracy, ISBN 978-9939-838-94-6, "Hayrapet" Publishing House, Yerevan 2020, pp. 256
}

From the point of view of social relations, the key issues include their stability and its derivative, namely - predictability. These, on the other hand, depend on political stability and predictability. The latter can be reduced to constitutional stability and predictability as the sine qua non condition of stable democracy. In other words, from the point of view of political and constitutional reflections, constitutional stability as a condition of stable democracy is the principal theoretical problem. The newest monographic study by an eminent Armenian researcher Anahit Manasyan "Constitutional Stability as an Important Prerequisite for Stable Democracy" is devoted to this question, which is fundamental for the doctrine of law. The book is dedicated to the study of a number of issues concerning the doctrine of democracy, axiological characteristics of constitutional stability, and the role of the latter in ensuring the democratization of society. The work is the first to complexly study the axiological characteristics of constitutional stability from the aspect of its role in ensuring democracy. Anahit Manasyan notices that the mechanisms of separating and balancing the powers change. The existing paradigms become inadequate in explaining the ongoing political processes. A necessity arises

ORCID ID: 0000-0002-8231-4454, Assoc. Prof., Faculty of Political Science and International Studies, University of Warsaw. E-mail: zalesnyjacek@gmail.com. 
to determine anew the relations taking place between the constitution, constitutionalism, and democracy, and hence de facto between law and politics.

The doctrine of democracy, issues of constitutional stability and constitutional developments, legal mechanisms of overcoming constitutional disputes, peculiarities of the official interpretation and direct application of the constitution, issues of the development of constitutional court legal positions, as well as the notion of «constitutional identity» and its axiological characteristics are studied in the frames of the monograph.

As the result - a number of theoretical conclusions are drawn, new theoretical concepts are developed and various practical proposals on the improvement of the legislation and law-enforcement practice are presented by the author.

The author mentions that though "democracy" is one of the widespread notions used in everyday life, both on the doctrinal level and in practice, the mentioned concept is not always perceived properly, and in some cases is presented and implemented in a distorted essence. Anahit Manasyan emphasizes that in particular, there is no complex research and uniform scientific approach on the limits of the power of people, which leads to distortion of the essence of the doctrine of democracy. In result - the author draws a considerable conclusion, according to which for the proper perception of the notion 'democracy' just the feature of the implementation of power by the people and for the people is not enough, and the doctrines of democracy need to be rethought. According to the author, the key point here should be the fact that democracy is a form of governance, within the frames of which people are the source of power, power is implemented by the people and for the people, having in the basis the human being as the highest value and being guided by the aim of guaranteeing for the latter possibilities for self-expression and self-realization.

Therefore, the essence of democracy is not the people being the source of power but the creation of legal and political frameworks to realize their rights and freedoms. The author concludes that the power of people is not an unlimited one and should be limited by fundamental human and citizen's rights and freedoms. Moreover, for the realization of the discussed aim of democracy choice of representatives of power based on the idea of elitism is necessary, taking as a basis the features of competence and professionalism. The 
author's very important finding is also that democracy is not a state of constans. People's needs are changing and the understanding of what is and what is not democratic must get modified, too. Therefore, the process of democratization as a permanent change of political relations within the frameworks of which people function comes to the fore.

Anahit Manasyan touches upon the concept "constitutional stability", concluding that stability is a feature of the Constitution and constitutional system, which presupposes viability of the Basic Law in conditions of reorganizing social relations. Moreover, in this context, it concerns not static, but dynamic stability, when the "core", the essence of the Constitution isn't subject to fundamental changes, but the Constitution itself can adapt to developing social relations, be a stimulus for their development.

Analyzing issues concerning the factors, conditioning constitutional stability, the author conditionally distinguishes them into two groups: 1. endogenous, 2. exogenous. The first group concerns the content of the Constitution and the nature of the internal constitutional solutions, for instance, self-efficiency of the Constitution. The second group includes all the external factors, which impact the determination of constitutional solutions and their viability, for instance, changes in the balance of political forces.

Analyzing issues relating to interrelations between constitutional stability and politics, the author substantiates that the Constitution should not be a tool for politics, but a bound, framework for it. Moreover, the constitutional developments should express not the current political preferences and interests, but be superior to them and define the fundamental legal framework for political actors and events. In other words, a constitutional policy should be differentiated from the ongoing politics, and the Constitution should not be a part of the current political game, itself defining the rules of that game. The Constitution must show the ability to adjust to the changing political needs. At the same time, however, this change should not be the answer to the current, singular problems which have to be solved in another way, without interference into the political foundations of the state.

Studying the frequency of constitutional amendments in various states, the author concludes that the Constitution should not be amended parallel with each change of the political situation in the state or formation of a new political majority. According to the author, Constitution is not just a docu- 
ment with the highest legal force, but also a symbol of a concrete constitutional system, and in this aspect, the Basic Law has a symbolic significance. Hence, the ways and frequency of constitutional amendments should form such a public perception that the Constitution is a stable document, a symbol of a concrete constitutional system, and cannot be amended just based on the political will of the political majority of the day.

Studying the issues concerning the development of the Constitution, Anahit Manasyan defines the term "development of the Constitution", according to which it is qualitative, directed and, as a rule, irreversible changes to the Basic Law, possessing peculiarity of internal interrelatedness and systemness, when the main quality of the system, the "core" of the Constitution is preserved.

The author also studies the idea of the "constitutionality of constitutional developments", concluding that notwithstanding its seeming paradoxicalness, the latter isn't a blank notion, is an important element of ensuring constitutionalism, has a concrete content and exceptional significance for ensuring stable democracy.

Anahit Manasyan's idea is also considerable that the constitutional preamble, besides the declaratory significance, has a constitutional value, practical importance and can be developed via other alternative ways, having as a key point the circumstance that the mentioned regulations are subject to dynamic interpretation, within the frames of which changes of perception of their separate elements are possible, simultaneously, the elements, constituting the «core», «kernel» of these principles, should be unchangeable.

From the viewpoint of efficiency of constitutional amendments, the importance of the combination of mechanisms of direct and representative democracies is emphasized, which is an important basis for professional decision-making, effective realization of the power of people and the aims of the latter, increasing the efficiency of administration, and in conditions of guaranteeing the other circumstances can mostly contribute to ensuring constitutional stability and strengthening stable democracy.

The author also substantiates that the development of the Constitution is impossible to carry out effectively only by way of making changes in its text and that interpretation is one of the most important means of the development of the Basic Law. 
The monograph studies the notion of «constitutional identity». The author presents her definition of the latter, according to which constitutional identity is the originality, individuality, and uniqueness of the concrete constitutional system. It includes not just the originally existing features, which provide the system quality of uniqueness, but also the features of the larger systems, which are borrowed by the constitutional system and with which the latter starts to identify itself.

The author also studies the methods and limits of the official interpretation of the Constitution. Anahit Manasyan's idea is notable, according to which the will of a constitutional legislator and the literal meaning of constitutional norms should not be the only basis for revealing the content of the latter, and that from the perspective of ensuring the stability and development of the Constitution it is expedient to apply dynamic interpretation. At the same time, it is emphasized that effective interpretation of the Constitution by the Constitutional Court, the observance of the principle of "efficient self-restraint" during its presupposed revealing of the content of constitutional norms, and deducing solutions to concrete constitutional problems in the frames of current constitutional regulations, as well as consistent and not an isolated application of the interpretation methods, are important elements of the process.

The monograph studies the notions "effect of the Constitution" and "application of the Constitution", making an interesting differentiation of them.

Studying the mechanisms of overcoming constitutional conflicts on competencies, an author's approach is presented on the notion and content of the latter. It is substantiated that the civilized method for the solution of the mentioned conflicts is their overcoming in the legal dimension. This presupposes the determination and realization of corresponding mechanisms of consideration of the mentioned cases at the Constitutional Court. The author concludes that in case of constitutional conflicts just its constitutional-legal element is subject to consideration at the Constitutional Court.

An author's approach on interrelations of the notions "independence" and "accountability" of the judicial power is also considerable. According to it, accountability is a characteristic peculiar for independent judicial power, does not contradict the essence of the latter, can in no case be perceived just as a mechanism of adopting decisions pleasant for the society, presupposes the necessity of accountability before the law, has corresponding assessment indi- 
cators, which themselves do not violate the boundaries of the independence of the judicial power, and should be materialized according to with approaches presented in respect to the realization of the limits of the power of people.

Summarizing, it should be noted that Anahit Manasyan's monograph "Constitutional Stability as an Important Prerequisite for Stable Democracy" is the first to complexly study the axiological characteristics of constitutional stability from the aspect of its role in ensuring democracy. What deserves to be emphasized includes the innovative character of the conducted scientific studies, their theoretical importance, as well as the rich and precisely proceeding justification. The book consists of a number of theoretical conclusions, new theoretical concepts, and various practical proposals on the improvement of the legislation and law-enforcement practice. Hence, it can be useful for a wide scope of readers interested in the issues of constitutional law, theory, and philosophy of law, sociology, politics. 